\title{
EFFICACY OF COMBINATION THERAPY OF METHOTREXATE WITH HYDROXYCHLOROQUINE OR SULFASALAZINE IN RHEUMATOID ARTHRITIS PATIENTS IN KUMAON REGION: A COMPARATIVE STUDY
}

\author{
Suyash Bharat ${ }^{1}$, Bhavana Srivastava ${ }^{2}$, Paramjeet Singh ${ }^{3}$, Reena Bhardwaj ${ }^{4}$, Sanjay Gaur ${ }^{5}$ \\ 1 Post Graduate Junior Resident, Department of Pharmacology, Government Medical College, Haldwani. \\ 2 Professor and Head, Department of Pharmacology, Government Medical College, Haldwani. \\ ${ }^{3}$ Associate Professor, Department of Medicine, Government Medical College, Haldwani. \\ ${ }^{4}$ Associate Professor, Department of Pharmacology, Government Medical College, Haldwani. \\ 5 Associate Professor, Department of Pharmacology, Government Medical College, Haldwani.
}

\begin{tabular}{l}
\hline ABSTRACT \\
OBJECTIVE \\
To Compare the Efficacy of combination therapy of Methotrexate (MTX) and Hydroxychloroquine (HCQ) with MTX and \\
Sulfasalazine (SSZ) in Rheumatoid Arthritis (RA) patients of Kumaon region.
\end{tabular}

\section{METHODS}

RA patients of age group in between 18-60 years, a definite rheumatoid arthritis patients based on 2010 ACR/EULAR CRITERIA, presenting to the medicine OPD with Disease Activity Score 28 (DAS 28) Score $>3.2$ were included in the study, and patients receiving treatment combinations were divided into study groups. In the OPD, HCQ was given at a dosage of $200 \mathrm{mg}$ twice a day, whereas dosage of MTX was 10 to $20 \mathrm{mg} /$ week. The dosage of SSZ was $500 \mathrm{mg}$ to $1000 \mathrm{mg}$ twice a day. The primary end point of the study was based on EULAR DAS 28 response criteria at the end of study period.

\section{RESULTS}

The mean values of DAS 28 score show statistical significant decline within the group in every follow-up and during $2^{\text {nd }}$ and $3^{\text {rd }}$ follow-ups DAS 28 score between 2 groups shows statistical significant difference. At the end of study period (6 months), the difference between 2 study groups was not statistically significant. According to EULAR RESPONSE CRITERIA, good response was seen in 26 patients from group $1^{\text {st }}$ and 27 patients from group $2^{\text {nd. }}$.

\section{CONCLUSION}

The efficacy of drug combinations, i.e. MTX plus SSZ and MTX plus HCQ, in treating Rheumatoid Arthritis patients are comparable. Combination of MTX plus SSZ, however, shows rapid decrease in disease activity as compared to combination of MTX plus HCQ.

\section{KEYWORDS}

Rheumatoid Arthritis, Methotrexate, Hydroxychloroquine, Sulfasalazine.

HOW TO CITE THIS ARTICLE: Bharat S, Srivastava B, Singh P, et al. Efficacy of combination therapy of methotrexate with hydroxychloroquine or sulfasalazine in rheumatoid arthritis patients in Kumaon region: a comparative study. J. Evolution Med. Dent. Sci.2016;5(51):3303-3307, DOI: 10.14260/jemds/2016/765

\section{INTRODUCTION \\ Rheumatoid Arthritis (RA) is a chronic inflammatory disease that causes joint pain, progressive joint destruction and functional disability, due to the combined effect of chronic synovitis and progressive joint damage. ${ }^{1} \mathrm{RA}$ affects the small synovial joints of hands and feet in a typical symmetrical distribution. This synovial inflammation may lead to cartilage damage and periarticular bone erosion and is manifested clinically by pain and deformities. These function limiting deformities and extra-articular manifestations adversely affects the quality of life in RA patients. Various studies have shown the efficacy of combination therapy over monotherapy.}

Financial or Other, Competing Interest: None.

Submission 11-05-2016, Peer Review 04-06-2016,

Acceptance 10-06-2016, Published 27-06-2016.

Corresponding Author:

Dr. Suyash Bharat,

Post Graduate Junior Resident,

Department of Pharmacology,

Government Medical College,

Haldwani, Rampur-263139,

Uttarakhand.

E-mail: dr.suyash.bharat@gmail.com

DOI: $10.14260 /$ jemds/2016/765
The DAS 28 is a measure of disease activity in Rheumatoid arthritis. DAS stands for 'disease activity score' and the number 28 refers to the 28 joints that are examined in this assessment.

Joint damage in rheumatoid arthritis begins early. Hence, treatment of RA now involves early initiation of Disease Modifying Anti-Rheumatic Drugs (DMARD) to slow the disease progress. Treatment of disease in the first months of synovitis is important to retard radiographic progression. ${ }^{2}$ This window of opportunity suggests that disease activity in patients with early RA is less severe, is characterized by a smaller load of inflammatory cells and is more responsive to treatment. So aggressive treatment during this phase is more likely to succeed than is the same treatment applied later in the course of disease when autoantigens from damaged joints possibly fuel the disease. ${ }^{3}$ Therefore, it is important that RA should be treated and controlled as soon as possible after diagnosis and that this control should be maintained for as long as possible, consistent with patient safety. 4,5

Various studies conclude that early start of DMARDs proved to be more efficacious than a delayed introduction of DMARDs in the disease progress of RA.6,7 More recent therapeutic strategies are based on combinations of DMARDs 
to control inflammation in the critical early stages of RA.8,9,10 Hence, the present study aimed to find out the efficacy of combination of DMARDS in producing early disease remission and arresting progression of disease process in RA patients of Kumaon region.

\section{METHODS}

This was a single centre prospective open labelled study, which was undertaken for a study period of 1 year, i.e. from January 2014 to January 2015 duly after taking permission from the Institutional Ethical Committee. This study was conducted in Department of Pharmacology and Outpatient Department (OPD) of Medicine of Government Medical College and Susheela Tiwari Government Hospital, Haldwani, Uttarakhand. This study was conducted on definite Rheumatoid Arthritis patients; based on 2010 ACR/EULAR CRITERIA, coming to medicine OPD. 11 The study population involved in this study was treatment naive or chronic cases of RA patients in Kumaon Region. Due written informed consent was obtained from the patients before the recruitment. The consent was explained in vernacular language to the patients, i.e. Hindi. Patients of age group 18-60 years were included in the study with DAS 28 score $>3.2$. Patient with uncontrolled diabetes mellitus, severe congestive heart failure, interstitial lung disease, active peptic ulcer, inflammatory bowel disease, malignancies, abnormal renal function, abnormal hepatic function, anaemia, leukopenia, thrombocytopenia, pregnant or lactating female patients; patients on biologic DMARD therapy were excluded from the study.

After obtaining the results from baseline investigations, patients meeting the criterias of the study were allotted one of the 2 groups. Group I was given tab Methotrexate 0.3 $\mathrm{mg} / \mathrm{kg} /$ week p.o. with tab Hydroxychloroquine $200 \mathrm{mg}$ p.o. once daily, whereas Group II was given tab Methotrexate 0.3 $\mathrm{mg} / \mathrm{kg} /$ week p.o. with tab Sulfasalazine $30 \mathrm{mg} / \mathrm{kg}$ body weight p.o. in divided doses. All patients were given folate supplementation. Patients were also given concomitant medication like NSAIDs, Calcium supplements, Vitamin D, etc.

To measure the outcomes of the treatment groups, DAS 28 was used to measure the disease activity. DAS 28 provides with a scale indicating current disease activity. If patient's DAS 28 score is less than 2.6 , he was considered in remission which means a state of absence of disease activity. The primary end point of the study was based on EULAR DAS 28 response Criteria at the end of study period. 12

For statistical analysis, SPSS version 21 was used. Differences in the mean values of the clinical outcome variables in the study groups were evaluated by Independent Sample ' $T$ ' test and to compare the DAS 28 score within the group on subsequent follow-ups. Paired sample ' $\mathrm{T}$ ' test was used. For this study, the Confidence Interval percentage was $90 \%$ and result was considered significant if the P-value was less than 0.1 .

\section{RESULT}

\section{Demographic Data}

The mean age of patients who participated in the study was 45.98 and 45.72 years in group I and group II respectively (Table 1).

In this study, patients of age between 18 to 60 years were included. Age group 51-60 years had maximum number of patients, i.e. 18 patients in group I and 18 patients in group II (Table 2).

\section{Baseline Characteristics (Table 3)}

In both the groups, patients with Rheumatoid factor and CReactive protein positive are comparable. Mean age since which patients are on DMARDs are 0.82 and 1.24 in group I and group II respectively.

\section{Disease Activity Score (DAS 28) (Table 4) (Figure 1)}

Mean Baseline values of DAS 28 in group I and group II were $5.38 \pm 0.68$ and $5.31 \pm 0.61$ respectively. These values showed steady and statistically significant $(\mathrm{p}<0.05)$ decline over every follow-ups and at the end of study period group I and group II had DAS 28 of $3.13 \pm 0.64$ and $3.02 \pm 0.57$ respectively. During $2^{\text {nd }}$ and $3^{\text {rd }}$ follow-ups, the difference in mean values of DAS 28 of group I and group II were statistically significant $(p<0.1)$.

\section{EULAR Response Criteria in both Groups (Table 5)}

According to EULAR response criteria, 26 patients from group I and 27 patients from group II showed good response and the rest showed moderate response to the drugs.

\section{Remission}

In the present study, the 10 patients from both group I and group II achieved their remission at the end of 6 months, that is DAS 28 score less than 2.6 .

\begin{tabular}{|c|c|c|}
\hline $\begin{array}{c}\text { Characteristics of the } \\
\text { Study Patients }\end{array}$ & Group I & Group II \\
\hline No. of patients (n) & 50 & 50 \\
\hline Age in years (mean \pm SD) & $45.98(9.54)$ & $45.72(9.65)$ \\
\hline$\%$ female & $88 \%$ & $86 \%$ \\
\hline Age of onset (mean \pm SD) & $41.96(9.15)$ & $40.99(9.67)$ \\
\hline $\begin{array}{c}\text { Family history positive } \\
\text { n (\%) }\end{array}$ & $8(16 \%)$ & $9(18 \%)$ \\
\hline \multicolumn{2}{|c|}{ Table 1: Demographic Data of the Study Patients } \\
\hline
\end{tabular}

\begin{tabular}{|c|c|c|}
\hline Age Group (In years) & Group I (n) & Group II (n) \\
\hline$<20$ & 0 & 1 \\
\hline $21-30$ & 2 & 3 \\
\hline $31-40$ & 16 & 13 \\
\hline $41-50$ & 14 & 15 \\
\hline $51-60$ & 18 & 18 \\
\hline \multicolumn{3}{|c|}{ Table 2: Age Distribution } \\
\hline
\end{tabular}

$*_{\mathrm{n}}$ - number of patients

\begin{tabular}{|c|c|c|c|}
\hline \multicolumn{2}{|c|}{$\begin{array}{l}\text { Characteristics of the } \\
\text { Study Patients }\end{array}$} & Group I & Group II \\
\hline \multicolumn{2}{|c|}{$\begin{array}{l}\text { Since when on DMARDs } \\
\text { (In years) }\end{array}$} & 0.82 & 1.24 \\
\hline \multirow{3}{*}{$\begin{array}{c}\text { Rheumatoid } \\
\text { factor positive, } \\
\% \\
\text { (Number of } \\
\text { patients) }\end{array}$} & Total & $50 \%,(25)$ & $56 \%,(28)$ \\
\hline & Male & $12 \%,(6)$ & $12 \%,(6)$ \\
\hline & Female & $38 \%,(19)$ & $44 \%,(22)$ \\
\hline \multirow{3}{*}{$\begin{array}{l}\text { C-Reactive } \\
\text { Protein, } \\
\text { positive, \% } \\
\text { (Number of } \\
\text { patients) }\end{array}$} & Total & $42 \%,(21)$ & $42 \%,(21)$ \\
\hline & Male & $6 \%,(3)$ & $8 \%,(4)$ \\
\hline & Female & $36 \%,(18)$ & $34 \%,(17)$ \\
\hline
\end{tabular}




\begin{tabular}{|c|c|c|c|}
\hline & $\begin{array}{c}\text { Group I } \\
\text { (MEAN } \pm \text { SD) }\end{array}$ & $\begin{array}{c}\text { Group II } \\
(\text { MEAN } \pm \text { SD) }\end{array}$ & P value \\
\hline Baseline & $5.38(0.68)$ & $5.31(0.61)$ & 0.58 \\
\hline $1^{\text {ST }}$ Follow Up & $4.36(0.64)$ & $4.29(0.49)$ & 0.58 \\
\hline $2^{\mathrm{ND}}$ Follow Up & $4.13(0.54)$ & $3.94(0.47)$ & $0.057^{*}$ \\
\hline $3^{\mathrm{RD}}$ Follow Up & $3.81(0.67)$ & $3.58(0.58)$ & $0.072^{*}$ \\
\hline $4^{\mathrm{TH}}$ Follow Up & $3.49(0.65)$ & $3.28(0.60)$ & 0.099 \\
\hline $5^{\mathrm{TH}}$ Follow Up & $3.13(0.64)$ & $3.02(0.57)$ & 0.36 \\
\hline \multicolumn{4}{|c|}{ Table 4: Comparing the Disease Activity Score } \\
(DAS 28) of 2 Groups \\
\hline
\end{tabular}

$\left({ }^{*} \mathrm{p}<0.1\right)$

\begin{tabular}{|c|c|c|}
\hline & $\begin{array}{c}\text { Group I } \\
\text { (No. of Patients) }\end{array}$ & $\begin{array}{c}\text { Group II } \\
\text { (No. of Patients) }\end{array}$ \\
\hline No Response & 0 & 0 \\
\hline $\begin{array}{c}\text { Moderate } \\
\text { Response }\end{array}$ & 24 & 23 \\
\hline $\begin{array}{c}\text { Good } \\
\text { Response }\end{array}$ & 26 & 27 \\
\hline \multicolumn{2}{|c|}{ Table 5: The EULAR Response Criteria in Both Groups } \\
\hline
\end{tabular}

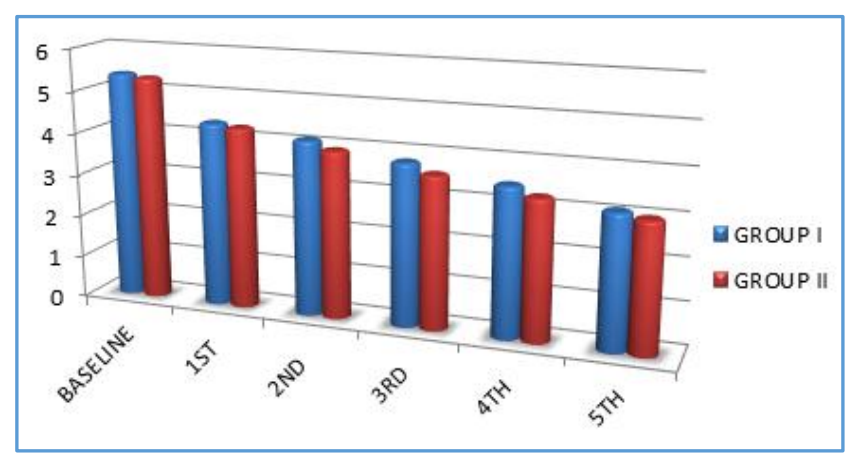

Fig. 1: Disease Activity Score 28 (DAS 28)

\section{DISCUSSION}

Rheumatoid arthritis is a debilitating, autoimmune, inflammatory disease that affects the joints of the body that are lined with synovium. The prevalence of Rheumatoid arthritis in the adult Indian population is $0.75 \% .13$

Methotrexate is a very frequently used DMARD for Rheumatoid arthritis.14 In the Indian scenario, Hydroxychloroquine and Methotrexate were the most frequently used combination of DMARDS. ${ }^{15}$ Various global studies had concluded that combination DMARD therapy is effective in Rheumatoid arthritis. The evidence is strongest in established Rheumatoid arthritis for combinations of Methotrexate with anti-TNF and/or SulfasalazineHydroxychloroquine given to patients who have partially responded to DMARD monotherapy. 16

The DAS 28 is a frequent outcome measure used in therapeutic trials. In the present study, the mean values of disease activity score in 28 joints (DAS 28) in Rheumatoid Arthritis patients at baseline in group I and group II were $5.38 \pm 0.68$ and $5.31 \pm 0.61$ respectively as seen in an Indian study. ${ }^{13}$

With combination therapy in both treatment groups, the mean values of Disease Activity Score (DAS28) showed steady decline with every monthly followup. On $2^{\text {nd }}$ and $3^{\text {rd }}$ follow-ups statistically significant difference was noted between the two treatment groups, which showed that group II had rapid decline in DAS 28 score when compared with group I. Some of the studies have shown that the improvement with Sulfasalazine was more rapid than Hydroxychloroquine.17,18 However, at the end of study period, group I and group II had mean disease activity scores (DAS 28) were $3.13 \pm 0.64$ and $3.02 \pm 0.57$ respectively with no significant difference statistically. An Indian study which in comparison to present study data had similar DAS 28 value at the baseline and the end of 6 months in treatment group Methotrexate and HCQ reported $7.1 \pm 1.04$ to $4.4 \pm 1.77$ respectively. ${ }^{19}$ In a study by Schipper L et al, which concurs with the present data states that at the end of 6 months the patients have been given Methotrexate and Sulfasalazine reported Mean \pm SD values of DAS 28 score, $4.0 \pm 1.3 .{ }^{20}$ The study suggests that no statistically significant difference in DAS 28 score was seen in both the groups, but the patients who had been given Methotrexate and Sulfasalazine showed early reduction in disease activity as compared to Methotrexate and Hydroxychloroquine group, and as mentioned earlier that it is important that RA should be treated and controlled as soon as possible after diagnosis. ${ }^{4,5}$ So here group II shows rapid decrease in disease activity when compared with group I.

The EULAR response criteria classify individual patients as non-, moderate or good responders depending on the extent of change and the level of disease activity reached. For clinical studies, valid tools for interpretation of group results during follow-up have been developed. The EULAR response criteria depending on the DAS/DAS 28 - value achieved at endpoint and the magnitude of change from baseline. ${ }^{12}$ In the present study, EULAR response criteria were evaluated and 26 (52\%) patients from group I showed good response and rest 24 (48\%) gave moderate response. Similar global study conducted in African RA patient treated with Methotrexate and Hydroxychloroquine showed similar results, i.e. 53.9\% showed good response using EULAR response criteria, but only $12.7 \%$ showed moderate response which do not harmonize with study data. ${ }^{21}$ In 24 (48\%) patients from group II with respect to EULAR good response was observed, while in $26(52 \%)$ patients, it was a moderate response. While comparing with a study in which Methotrexate and Sulfasalazine, DMARD combination were given, $38 \%$ of the patients reported good response and $34 \%$ patients reported moderate response.22

In general, remission means the state of absence of disease activity in patients with a chronic illness with the possibility of returning disease activity. In RA, remission predicts preserving the functional capacity as well as retarding the radiographic progression. ${ }^{23}$ In clinical studies, the definition of remission has to be unambiguous. Numerical limits of disease activity are commonly used; DAS 28 below 2.6 are considered to represent the state of remission. 24

In the present study, at the end of study period ( $5^{\text {th }}$ follow-up), 10 (20\%) patients from both group I and group II had DAS 28 score less than or equal to 2.6. An international study in which Methotrexate is given along with Hydroxychloroquine or Sulfasalazine or other conventional synthetic DMARDs achieved remission in $7 \%$ of the patients. ${ }^{25}$ Another Asian multicenter cross-sectional study gave remission rates of $\mathrm{RA}$, which were $8.6 \%$ (DAS28 $\leq 2.6$ ) when treated with Methotrexate and Hydroxychloroquine. 26 
The present study has its limitations, as RA is a chronic disease, so shorter duration of study 6 months might have concealed some findings. Patients were allowed to take concomitant medication, which might have affected the efficacy of the study drugs to some extent. So study needs to be validated with randomised double blind studies.

The study recommends the use of Sulfasalazine and Methotrexate combination as an alternative to Methotrexate and Hydroxychloroquine in RA patients with the advantage that this combination provides early relief in symptoms.

\section{CONCLUSION}

The efficacy of drug combinations, i.e. Methotrexate plus Sulfasalazine and Methotrexate plus Hydroxychloroquine in treating Rheumatoid Arthritis patients are comparable. Combination of Methotrexate plus Sulfasalazine, however, shows rapid decrease in disease activity as compared to combination of Methotrexate plus Hydroxychloroquine.

\section{ACKNOWLEDGMENT}

The authors thank Dr. Renu Khanchandani, Dr. Pulkit Nag. We also would like to thank Mr. Subham Pandey for assistance with statistics.

\section{REFERENCES}

1. Pollard L, Choy EH, Scott DL. The consequences of rheumatoid arthritis: quality of life measures in the individual patient. Clin Exp Rheumatol 2005;23(5 Suppl 39):S43-52.

2. Raza K, Buckley CE, Salmon M, et al. Treating very early rheumatoid arthritis. Best Pract Res Clin Rheumatol 2006;20(5):849-63.

3. Boers M. Understanding the window of opportunity concept in early rheumatoid arthritis. Arthritis Rheum 2003;48(7):1771-4.

4. Moreland LW, Russell AS, Paulus HE. Management of rheumatoid arthritis: the historical context. J Rheumatol 2001;28(6):1431-52.

5. Wolfe F, Cush JJ, O'Dell JR, et al. Consensus recommendations for the assessment and treatment of rheumatoid arthritis. J Rheumatol 2001;28(6):1423-30.

6. Smolen JS, Aletaha D, Machold KP. Therapeutic strategies in early rheumatoid arthritis. Best Pract Res Clin Rheumatol 2005;19(1):163-77.

7. Van der Heide A, Jacobs JW, Bijlsma JW, et al. The effectiveness of early treatment with "second-line" antirheumatic drugs. A randomized, controlled trial. Ann Intern Med 1996;124(8):699-707.

8. Capell HA, Madhok R, Porter DR, et al. Combination therapy with sulfasalazine and methotrexate is more effective than either drug alone in patients with rheumatoid arthritis with a suboptimal response to sulfasalazine: results from the double-blind placebocontrolled MASCOT study. Ann Rheum Dis 2007;66(2):235-41.

9. Landewe RB, Boers $M$, Verhoeven AC, et al. COBRA combination therapy in patients with early rheumatoid arthritis: long-term structural benefits of a brief intervention. Arthritis Rheum 2002;46(2):347-56.

10. Wilske KR, Healey LA. Remodeling the pyramid: a concept whose time has come. J Rheumatol 1989;16(5):565-7.
11. Aletaha D, Neogi T, Silman AJ, et al. 2010 rheumatoid arthritis classification criteria: an American College of Rheumatology/European league against rheumatism collaborative initiative. Arthritis Rheum 2010;62(9):2569-81.

12. vanGestel AM, Prevoo ML, van't Hof MA, et al. Development and validation of the European league against rheumatism response criteria for rheumatoid arthritis. Comparison with the preliminary American college of rheumatology and the World Health Organization/International league against rheumatism criteria. Arthritis Rheum 1996;39(1):34-40.

13. Malaviya AN, Kapoor SK, Singh RR, et al. Prevalence of rheumatoid arthritis in the adult Indian population. Rheumatol In 1993;13(4):131-4.

14. Aletaha D, Smolen JS. The rheumatoid arthritis patient in the clinic: comparing more than 1,300 consecutive DMARD courses. Rheumatology (Oxford) 2002;41(12):1367-74.

15. Singh NR. Treatment of rheumatoid arthritis with combination of disease modifying anti-rheumatic drugs: a three-year folloe-up study. IJPMR 2001:11-8.

16. Choy EHS, Smith C, Dore CJ, et al. A meta-analysis of the efficacy and toxicity of combining disease-modifying antirheumatic drugs in rheumatoid arthritis based on patient withdrawal. Rheumatology 2005;44:1414-21.

17. Nuver-Zwart IH, van Riel PL, van de Putte LB, et al. A double blind comparative study of sulfasalazine and hydroxychloroquine in rheumatoid arthritis: evidence of an earlier effect of sulfasalazine. Ann Rheum Dis 1989;48(5):389-95.

18. Faarvang KL, Egsmose $\mathrm{C}$, Kryger $\mathrm{P}$, et al. Hydroxychloroquine and sulfasalazine alone and in combination in rheumatoid arthritis: a randomized double blind trial. Ann Rheum Dis 1993;52(10):711-5.

19. Ghosh B, Halder S, Ghosh A, et al. Early rheumatoid arthritis: clinical and therapeutic evaluation in a tertiary care centre in India. Indian Journal of Rheumatology 2008;3(2):48-51.

20. Schipper LG, Fransen J, Barrera P, et al. Methotrexate therapy in rheumatoid arthritis after failure to sulfasalazine: to switch or to add? Rheumatology 2009;48(10):1247-53.

21. Ndongo S, Pouye A, Lekpa FK, et al. Disease modifying treatment for inflammatory rheumatism in sub Saharan Africa: outcome at 6 months of 205 senegalese patients with rheumatoid arthritis. Med Sante Trop 2012;22(4):385-9.

22. Dougados M, Combe B, Cantagrel A, et al. Combination therapy in early rheumatoid arthritis: a randomised, controlled, double blind $52 \hat{\mathrm{A}}$ week clinical trial of sulfasalazine and methotrexate compared with the single components. Annals of the Rheumatic Diseases 1999;58(4):220-5.

23. van Tuyl LH, Felson DT, Wells G, et al. Evidence for predictive validity of remission on long-term outcome in rheumatoid arthritis: a systematic review. Arthritis Care Res (Hoboken) 2010;62(1):108-17.

24. Prevoo ML, van 't Hof MA, Kuper HH, et al. Modified disease activity scores that include twenty-eight-joint counts. Development and validation in a prospective longitudinal study of patients with rheumatoid arthritis. Arthritis Rheum 1995;38(1):44-8. 
25. Fleischmann R, Koenig A, Szumski A, et al. Short-term efficacy of etanercept plus methotrexate vs combinations of disease-modifying anti-rheumatic drugs with methotrexate in established rheumatoid arthritis. Rheumatology 2014;53(11):1984-93.
26. Wang G, Zhang S, Wang X, et al. Remission of rheumatoid arthritis and potential determinants: a national multicenter cross-sectional survey. Clin Rheumatol 2014;34(2):221-30. 